\title{
Demographic Profiles and Sources of Infection among Septic Patients admitted at ICU of a Public Hospital in Dhaka City
}

\author{
Subroto Kumar Sarker ${ }^{1}$, Mohammod Saiful Azam², Montosh Kumar Mondal ${ }^{3}$, Uday Kumar \\ Goswami $^{4}$, Mohammad Mohsin ${ }^{5}$
}

\begin{abstract}
${ }^{1}$ Assistant Professor, Department of Critical Care Medicine, Dhaka Medical College, Dhaka, Bangladesh; ${ }^{2}$ Junior Consultant (Medicine), ...............................; ${ }^{3}$ Associate Professor, Department of Anaesthesia, Analgesia and Intensive Care Medicine, Bangabandhu Sheikh Mujib Medical University, Dhaka, Bangladesh; ${ }^{4}$ Assistant Professor, Department of Oral and Maxillofacial Surgery, Dhaka Medical College, Dhaka, Bangladesh; ${ }^{5}$ Assistant Professor, Department of Critical Care Medicine, Dhaka Medical College, Dhaka, Bangladesh
\end{abstract}

[Received: 12 November 2020; Accepted: 30 November 2020; Published: 1 December 2020]

\begin{abstract}
Background: Sepsis occurs due to different sources of infection. Objective: The purpose of the present study was to see the demographic profiles and sources of infection among septic patients admitted at ICU of a public hospital in Dhaka City. Methodology: This descriptive cross sectional study was conducted in the Intensive Care Unit of the department of Anaesthesia Analgesia, Palliative and Intensive Care Medicine, Dhaka Medical College Hospital, Dhaka, Bangladesh over a period of 12 months starting from January 2016 to December 2016. All patients admitted to ICU with the features of severe sepsis and septic shock according to SSC guidelines with the age of more than or equal to 18 years in both sexes were set as selection criteria for this study. Instruments required to perform the study were data sheet addressing the demographic data, primary source of severe sepsis and organ dysfunctions. BSepsis was confirmed by detection of serum lactate and culture of blood. Result: A total number of patients was 69 cases. The mean with SD was $38.72 \pm 13.43$ with the age range of patient 18 to 65 year. The male and female ratio was $1.7: 1$. The most common source of infection were abdomen which was $30(43.5 \%)$ cases followed by CNS, respiratory tract, urogenital tract and GIT which were $(21.7 \%)$ cases, $(14.5 \%)$ cases, $(17.4 \%)$ cases and $(2.9 \%)$ cases respectively. Among the 69 patient 20 patients were blood cultures positive, 15 patients were pus culture positive, 10 patients were urine/catheter tip culture positive. Conclusion: In conclusion young adult male is most commonly suffering from sepsis in ICU mostly due to infection of abdomen. [Bangladesh Journal of Infectious Diseases, December 2020;7(2):40-43]

Keywords: Demographic profiles; sources of infection; septic patients; ICU

Correspondence: Dr. Subroto Kumar Sarker, Assistant Professor, Department of Critical Care Medicine, Dhaka Medical College, Dhaka, Bangladesh; Email: subrotormc@ @mail.com; Cell no.: +8801711066763

Conflict of interest: Authors declare that there is no conflict of interests.

Funding agency: The study was not funded by any authority.

Contribution to authors: Sarker SK, Azam MS, Mondal MK involved in protocol preparation, data collection and literature search up to manuscript writing. Mondal MK, Goswami UK, Mohsin M involved in literature search, preparation and revision of this manuscript.

How to cite this article: Sarker SK, Azam MS, Mondal MK, Goswami UK, Mohsin M. Demographic Profiles and Sources of Infection among Septic Patients admitted at ICU of a Public Hospital in Dhaka City. Bangladesh J Infect Dis 2020;7(2):40-43

Copyright: ( 2020 . Sarker et al. Published by Bangladesh Journal of Infectious Diseases. This article is published under the Creative Commons CC BY-NC License (https://creativecommons.org/licenses/by-nc/4.0/). This license permits use, distribution and reproduction in any medium, provided the original work is properly cited, and is not used for commercial purposes.
\end{abstract}




\section{Introduction}

Sepsis is a major cause of morbidity and mortality. It is the second leading cause of death worldwide ${ }^{1}$. The incidence of severe sepsis and the number of sepsis related death is increasing. Sepsis is now the $10^{\text {th }}$ most common cause of death in the united states $^{2}$.The definition of severe sepsis and septic shock has been formulated since early 1990s and has been accepted worldwide ${ }^{3}$. So when sepsis is associated with hypo perfusion or single organ dysfunction it becomes severe sepsis. When hypoperfusion persists in spite of adequate fluid resuscitation and requiring vasopressors, it is called septic shock ${ }^{4}$.

Sepsis is a major challenge in medicine. Massive resources have been invested in developing and evaluating potential therapies and considerable effort has been undertaken to understand the systemic inflammation and multiple-system organ failure characteristics of severe sepsis ${ }^{5}$. An early strategy of quantitative resuscitation enables a decrease in mortality rate of septic patients, but few data are available for prolonged intensive care unit (ICU) strategy ${ }^{6}$.

When an organ system begins to fail because of sepsis, the condition is considered severe and is one of the leading causes of death in the critically ill, with the mortality rate of 28.0 to $55.0 \%$ cases $^{7}$. The purpose of the present study was to see the demographic profiles and sources of infection among septic patients admitted at ICU of a public hospital in Dhaka City.

\section{Methodology}

This was descriptive cross sectional study. This study was conducted in the Intensive Care Unit of the department of Anaesthesia Analgesia, Palliative and Intensive Care Medicine, Dhaka Medical College Hospital, Dhaka. This study was carried out over a period of 12 months starting from January 2016 to December 2016. All adult patients admitted in the Intensive Care Unit, with the features of severe sepsis and septic shock who fulfilled the selection criteria. Purposive sampling technique was applied for collection of the sample. All patients admitted to ICU with the features of severe sepsis and septic shock according to SSC guidelines with the age of more than or equal to 18 years in both sexes were set as selection criteria for this study. Appropriate data were collected by using a preformed data sheet. Other necessary data were collected from history sheet and investigation papers. Instruments required to perform the study were data sheet addressing the demographic data, primary source of severe sepsis and organ dysfunctions. All patients who were admitted to the ICU and fulfill the SIRS criteria during a 12-month period were examined and data was recorded in the preformed structured data sheet. After meeting inclusion criteria and who fulfill the diagnostic criteria for sepsis was evaluated. Sepsis is defined as the presence of infection together with systemic manifestations of infection i.e. systemic inflammatory response syndrome (SIRS). Following the detailed information, informed written consent of the patient and/or guardian was obtained. Then detailed history and physical examination were performed and primary source of infection was identified. After that arterial and central lines were inserted. Then arterial and central venous blood was collected for analysis. Then blood sample for serum lactate from arterial line was collected and specimen for culture was collected from primary source of infection. Data from each patient was collected in structured data sheets individually. Finally all data was compiled together and data were presented as mean with SD. All statistical analysis was performed by using the Statistical Package for Social Sciences version 16 for Windows (SPSS Inc., Chicago, Illinois, USA). Prior to the commencement of this study, the research protocol was approved by the Ethical Review Committee of the Dhaka Medical College.

\section{Result}

A total number of patients was 69 cases. The mean with SD was $38.72 \pm 13.43$ with the age range of patient 18 to 65 year. Majority of the patients were I the age group of 31 to 40 years which was $21(30.4 \%)$ followed by 21 to 30 years, 51 to 60 Years and 41 to 50 Years which were $18(26.1 \%)$ cases, $13(18.8 \%)$ cases and $8(11.6 \%)$ cases respectively (Table 1$)$.

Table 1: Distribution of Patients by Age (n=69)

\begin{tabular}{|l|c|c|}
\hline Age Group & Frequency & Percent \\
\hline$\leq 20$ Years & 5 & 7.3 \\
\hline 21 to 30 Years & 18 & 26.1 \\
\hline 31 to 40 Years & 21 & 30.4 \\
\hline 41 to 50 Years & 8 & 11.6 \\
\hline 51 to 60 Years & 13 & 18.8 \\
\hline More than 60 Years & 4 & 5.8 \\
\hline Total & $\mathbf{6 9}$ & $\mathbf{1 0 0 . 0}$ \\
\hline Mean \pm SD & $38.72 \pm 13.43$ \\
\hline Range (min-max) & \multicolumn{2}{|c|}{18.00 to 65.00} \\
\hline
\end{tabular}


In this study male was predominate than female which was $44(63.8 \%)$ cases and $25(36.2 \%)$ cases respectively. The male and female ratio was $1.7: 1$ (Table 2).

Table 2: Distribution of patients by sex $(n=69)$

\begin{tabular}{|l|c|c|}
\hline Gender & Frequency & Percent \\
\hline Male & 44 & 63.8 \\
\hline Female & 25 & 36.2 \\
\hline Total & $\mathbf{6 9}$ & $\mathbf{1 0 0 . 0}$ \\
\hline
\end{tabular}

The most common source of infection were abdomen which was 30(43.5\%) cases followed by CNS, respiratory tract, urogenital tract and GIT which were $(21.7 \%)$ cases, $(14.5 \%)$ cases, $(17.4 \%)$ cases and (2.9\%) cases respectively (Table 3 ).

Table 3: Distribution of Patients according to Source of Infection $(n=69)$

\begin{tabular}{|l|c|c|}
\hline Source of Infection & Frequency & Percent \\
\hline Abdomen & 30 & 43.5 \\
\hline CNS & 15 & 21.7 \\
\hline Urogenital tract & 12 & 17.4 \\
\hline Respiratory tract & 10 & 14.5 \\
\hline GIT & 2 & 2.9 \\
\hline Total & $\mathbf{6 9}$ & $\mathbf{1 0 0 . 0}$ \\
\hline
\end{tabular}

Among the 69 patient 20 patients were blood cultures positive, 15 patients were pus culture positive, 10 patients were urine/catheter tip culture positive, 5 patients were sputum/tracheal aspirate culture positive and 5 patients were CSF culture positive. Total 14 patients were culture negative (Table 4).

Table 4: Specimen of the Primary Source of Infection in Septic Patients

\begin{tabular}{|l|c|}
\hline Specimen for culture & Culture Positive \\
\hline Blood & 20 \\
\hline Pus & 15 \\
\hline Urine/ Catheter tip & 10 \\
\hline Sputum/ Tracheal aspirate & 5 \\
\hline CSF & 5 \\
\hline
\end{tabular}

\section{Discussion}

Severe sepsis and septic shock are very common in ICU in this study. A total 69 of patients fulfilled the criteria of severe sepsis and septic shock during the study period. The mean and SD of age in this study were $42.0 \pm 10.0$ years. Commonest age range was 31 to $40(30.4 \%)$ whom developed severe sepsis and septic shock.

Alberti et $\mathrm{al}^{8}$ epidemiologic studies of severe sepsis are difficult to compare, not only because their results are influenced by their date of implementation and the type of ICU analyzed, but also because severe sepsis is a highly heterogeneous condition.

Guidet et $\mathrm{al}^{9}$ compared non-severe sepsis patients with severe sepsis patients and found that severe sepsis patients were significantly older and had male predominance. In this study $63.8 \%(\mathrm{n}=44)$ were male \& $36.2 \%(n=25)$ were female. Most of the sepsis patients of this study were from surgical, casualty, gynae \& obstetric and medicine ward. Probably younger age in my study was due to poor isolation facility and poor hygienic conditions and lack of awareness of these patients increases septic condition even in younger ages.

In this study, the most common source of infection was abdomen $(43.5 \%)$, CNS $(21.7 \%)$, respiratory tract $(14.5 \%)$, urogenital tract $(17.4 \%)$ and GIT (2.9\%). Zahorec et $\mathrm{al}^{10}$ conduct epidemiology of sepsis in Slovak Republic and revealed respiratory and renal dysfunction was the most frequent organ dysfunctions in $52.0 \%$ and $42.2 \%$, respectively and the most frequent sites of infection were the respiratory tract $(62.9 \%)$ and the abdomen $(25.3 \%)$.

In another study, it has been reported that the main source of sepsis is urinary tract infections, followed by skin/soft tissue infections, lower respiratory tract infection and gallbladder/bile ducts infections ${ }^{11}$. These four sources represented almost $91.0 \%$ of the episodes reported. Previously published studies ${ }^{12-14}$ found that the most common source of sepsis is lower respiratory tract infections, intra-abdominal, and urinary tract infections and Gram-negative microorganisms from genitourinary tract and intraabdominal infections are the leading causes of sepsis.

\section{Conclusion}

In conclusion young adult age group is the maximum number of patients who are suffering from sepsis. Furthermore male is predominant than female. Considering the source of infection the patients with infection of abdomen are the main source of infection; furthermore central nervous system and respiratory infection are also the important sources of infection among the ICU patients. Large scale multicenter study should be carried out to see the real scenario of the country. 


\section{References}

1. Lever A, Mackenzie I. Sepsis: definition, epidemiology, and diagnosis. Bmj. 2007;335(7625):879-83

2. Martin GS, Mannino DM, Eaton S, Moss M. The epidemiology of sepsis in the United States from 1979 through 2000. New England Journal of Medicine. 2003;348(16):154654.

3. Vincent JL, Rello J, Marshall J, Silva E, Anzueto A, Martin CD, Moreno R, Lipman J, Gomersall C, Sakr Y, Reinhart K. International study of the prevalence and outcomes of infection in intensive care units. Jama. 2009;302(21):2323-9.

4. Nguyen HB, Rivers EP, Havstad S, Knoblich B, Ressler JA, Muzzin AM, et al. Critical care in the emergency department a physiologic assessment and outcome evaluation. Academic Emergency Medicine. 2000;7(12):1354-61.

5. Angus DC, Linde-Zwirble WT, Lidicker J, Clermont G, Carcillo J, Pinsky MR. Epidemiology of severe sepsis in the United States: analysis of incidence, outcome, and associated costs of care. Critical care medicine. 2001;29(7):1303-10.

6. Singer M, Deutschman CS, Seymour CW, Shankar-Hari M, Annane D, Bauer M, et al. The third international consensus definitions for sepsis and septic shock (Sepsis-3). JAMA 2016;315(8):801-10

7. Engel C, Brunkhorst FM, Bone HG, Brunkhorst R, Gerlach H, Grond S, Gruendling M, Huhle G, Jaschinski U, John S,
Mayer K. Epidemiology of sepsis in Germany: results from a national prospective multicenter study. Intensive care medicine. 2007;33(4):606-18.

8. Alberti C, Brun-Buisson C, Burchardi H, Martin C, Goodman S, Artigas A, et al. Epidemiology of sepsis and infection in ICU patients from an international multicentre cohort study. Intensive care medicine. 2002;28(2):108-21.

9. Guidet B, Aegerter P, Gauzit R, Meshaka P, Dreyfuss D, CUB-Réa Study Group. Incidence and impact of organ dysfunctions associated with sepsis. Chest. 2005;127(3):942-51 10. Zahorec R, Firment J, Strakova J, Mikula J, Malík P, Novák I, et al. Epidemiology of severe sepsis in intensive care units in the Slovak Republic. Infection. 2005;33(3):122-8.

11. de León-Rosales SP, Molinar-Ramos F, Domínguez-Cherit G, Rangel-Frausto SM, Vázquez-Ramos VG. Prevalence of infections in intensive care units in Mexico: A multicenter study. Critical care medicine. 2000;28(5):1316-21.

12. van Gestel A, Bakker J, Veraart CP, van Hout BA. Prevalence and incidence of severe sepsis in Dutch intensive care units. Critical care. 2004;8(4):R153.

13. Sundararajan V, MacIsaac CM, Presneill JJ, Cade JF, Visvanathan K. Epidemiology of sepsis in Victoria, Australia. Critical care medicine. 2005;33(1):71-80.

14. Padkin A, Goldfrad C, Brady AR, Young D, Black N, Rowan K. Epidemiology of severe sepsis occurring in the first $24 \mathrm{hrs}$ in intensive care units in England, Wales, and Northern Ireland. Critical care medicine. 2003;31(9):2332-8. 